
Technologies

\title{
Dispersive solid-phase extraction based on butylamide silica for the determination of sulfamethoxazole in milk samples by capillary electrophoresis
}

\author{
Gabriela Islas, José A. Rodríguez, M. Elena Páez-Hernández, Silvia Corona- \\ Avendaño, Alberto Rojas-Hernández \& Enrique Barrado
}

To cite this article: Gabriela Islas, José A. Rodríguez, M. Elena Páez-Hernández, Silvia Corona-Avendaño, Alberto Rojas-Hernández \& Enrique Barrado (2016) Dispersive solidphase extraction based on butylamide silica for the determination of sulfamethoxazole in milk samples by capillary electrophoresis, Journal of Liquid Chromatography \& Related Technologies, 39:14, 658-665, DOI: 10.1080/10826076.2016.1230551

To link to this article: http://dx.doi.org/10.1080/10826076.2016.1230551

Accepted author version posted online: 13

Sep 2016.

Published online: 13 Sep 2016.

Submit your article to this journal ¿

Џ Article views: 18

View related articles

View Crossmark data $₫$ 


\title{
Dispersive solid-phase extraction based on butylamide silica for the determination of sulfamethoxazole in milk samples by capillary electrophoresis
}

\author{
Gabriela Islas a, José A. Rodrígueza , M. Elena Páez-Hernández ${ }^{a}$, Silvia Corona-Avendañob, \\ Alberto Rojas-Hernández ${ }^{c}$, and Enrique Barrado ${ }^{d}$ \\ aÁrea Académica de Química, Universidad Autónoma del Estado de Hidalgo, Pachuca, Hidalgo, Mexico; 'bepartamento de Materiales, Área Ingeniería \\ de Materiales, Universidad Autónoma Metropolitana-Azcapotzalco, Ciudad de Mexico, Mexico; 'Departamento de Química, Área de Química \\ Analítica, Universidad Autónoma Metropolitana-Iztapalapa, Ciudad de Mexico, Mexico; dDepartamento de Química Analítica, Facultad de Ciencias, \\ Universidad de Valladolid, Valladolid, Spain
}

\section{ABSTRACT}

A new method based on the combination of dispersive solid-phase extraction and capillary electrophoresis is proposed for the determination of sulfamethoxazole in milk samples. Butylamide silica was synthesized and used as extractant. Factors involved in sample treatment method such as: butylamide silica amount, $\mathrm{NaOH}$ concentration in methanol, sample volume, and dispersion time were evaluated using a Taguchi parameter design. Under optimal conditions, average recoveries ranged from 73 to $85 \%$ with a limit of detection of $0.05 \mathrm{mg} \mathrm{L}^{-1}$ were achieved. The proposed method is a useful technique for cleanup milk samples.

GRAPHICAL ABSTRACT

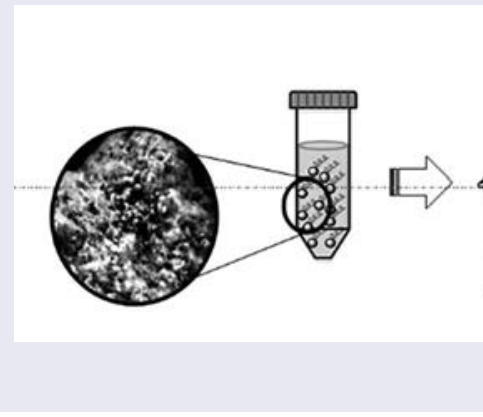

\section{Introduction}

The use of subtherapeutic doses of antibiotics in animals intended for human consumption is a common practice to prevent diseases and promote weight gain. ${ }^{[1]}$ One group of synthetic antibiotics most frequently used for these purposes are sulfonamides. ${ }^{[2]}$ In consequence, residues of sulfonamides can be found in animal tissues, milk, and also in environmental samples such as surface waters causing adverse effects in humans such as allergic reactions in hypersensitive people besides to induce high levels of bacterial resistance. ${ }^{[3-6]}$ The sulfamethoxazole (SMX) is a sulfonamide commonly administered in animals and humans. As a result, several methodologies for the analysis of SMX residues have been developed, including spectroscopic, ${ }^{[7]}$ electrochemical,${ }^{[8]}$ or separation techniques based on capillary electrophoresis ${ }^{[9]}$ and highperformance liquid chromatography. ${ }^{[10]}$

On the other hand, pretreatment of milk samples represents a challenge during the development of an analytical methodology for the determination of antibiotic residues. The milk matrix is complex and it requires different steps during the

\section{KEYWORDS}

Butylamide silica; capillary electrophoresis; dispersive solid-phase extraction; milk; sulfamethoxazole treatment of the sample, some of which are precipitation of proteins by decreasing the $\mathrm{pH}$ value or adding organic solvents (methanol or acetonitrile), filtration, and centrifugation. Additionally, preconcentration of analytes may be necessary, a liquid-liquid extraction ${ }^{[11,12]}$ or solid-phase extraction $(\mathrm{SPE})^{[13,14]}$ is required. SPE is the sample preparation technique most usually used for the analysis of antibiotic residues in foods; it is based on the passage of the sample through a solid extractant contained in a cartridge where the analytes are retained and subsequently eluted with a suitable solvent. ${ }^{[15,16]}$

Dispersive solid-phase extraction $(\mathrm{DSPE})^{[17,18]}$ was described as an alternative to SPE. To improve retention of the analytes, the solid phase is added to the liquid sample to form dispersion. The contact between the analyte and the solid extractant is higher than in classic SPE, providing a better interaction during analyte extraction, and in consequence, a time reduction of sample treatment. Additionally, DSPE has the advantage of being a microscale extraction method, which makes it an attractive alternative to preconcentrate different analytes in complex matrices. ${ }^{[17-19]}$ 
Some applications of DSPE for the determination of sulfonamides have been developed. It has been described by its application during the analysis of mineral water and pork tissue samples where the extractant phase was composed of carbon nanotubes which contributes to adsorption of the antibiotic through $\pi-\pi$ interactions. ${ }^{[17,18]}$ Recently, to enhance the use of solid phases, it has been proposed separation methodologies using solid phases that contain functional groups which are different from those conventionally used. As a result, the analytes can be retained by mixed mode interactions as hydrogen bonding and dipole-dipole interactions. ${ }^{[20-22]}$ These solid phases have been applied for the analysis of some drugs ${ }^{[10,23,24]}$ as well as pesticides. ${ }^{[19]}$ Milk samples have been analyzed through DSPE-RP-HPLC using silica modified with $\mathrm{N}$-propyl-ethylenediamine as extracting phase for the multiresidue determination of pesticides. This work presents the synthesis and evaluation of the butylamide silica in SMX determination in milk samples by DSPE combined with capillary electrophoresis.

\section{Experimental}

\section{Reagents and chemicals}

All solutions were prepared by dissolving the respective analytical grade reagent in deionized water with a resistivity not less than $18.0 \mathrm{M} \Omega \mathrm{cm}$, Milli-Q system (Millipore, Bedford, MA, USA). Sodium hydroxide, sodium phosphate monobasic, and acetic acid were obtained from Sigma-Aldrich (Steinheim, Germany). Methanol, acetonitrile, anhydrous toluene, and ethanol were from J.T. Baker (Phillipsburg, NJ, USA). 3-(Aminopropyl) trimethoxysilane (99\%, APTMS), tetramethylorthosilicate (98\%, TMOS), triethylamine (99\%), methyl acrylate (99\%), and butylamine (99.5\%), triton X-100, and cetyltrimethyl ammonium bromide (CTAB) were obtained from Sigma-Aldrich (St. Louis, MO, USA).

Sulfamethoxazole (99.9\%) was obtained from SigmaAldrich (Steinheim, Germany). The standard solution was prepared daily by the dilution of a stock solution $\left(100 \mathrm{mg} \mathrm{L}^{-1}\right)$ by dissolving the pure substance in methanol. The solution was stored in the dark and refrigerated at $4^{\circ} \mathrm{C}$ and renewed weekly. Doxycycline hyclate (98\%, from Sigma-Aldrich) was used as the internal standard (IS).

\section{Synthesis of the butylamide silica adsorbent}

Synthesis of butylamide silica was performed on the basis of sol-gel process. TMOS, 0.02 moles $(5.17 \mathrm{~mL})$, was previously solubilized in $25 \mathrm{~mL}$ of a solution containing $2.0 \%(\mathrm{w} / \mathrm{v})$ Triton $\mathrm{X}-100,0.02 \%(\mathrm{w} / \mathrm{v}) \mathrm{CTAB}, 12.5 \%(\mathrm{v} / \mathrm{v})$ methanol, and $1.0 \mathrm{~mL}$ of $\mathrm{NH}_{3} 28 \%(\mathrm{w} / \mathrm{w})$ as a catalyst. The mixture was refluxed for $16 \mathrm{~h}$ with stirring. ${ }^{[25]}$ Silica phase was then washed with distilled water, followed by ethanol $(3 \times 10 \mathrm{~mL}$ each one $)$, and dried at $100^{\circ} \mathrm{C}$ for $24 \mathrm{~h}$. In order to activate it, the silica $(3.0 \mathrm{~g})$ was immersed in $40 \mathrm{~mL}$ of $\mathrm{HCl} 3 \mathrm{M}$ and refluxed for $8 \mathrm{~h}$; later it was filtered, washed with distilled water, and dried at $120^{\circ} \mathrm{C}$ all night. Activated silica was mixed with $30 \mathrm{~mL}$ of anhydrous toluene, $0.5 \mathrm{~mL}$ of triethylamine, and $3 \mathrm{~mL}$ of APTMS; the mixture was refluxed for $24 \mathrm{~h}$. Propylamine functionalized silica was filtered, washed with toluene followed by ethanol $\left(3 \times 10 \mathrm{~mL}\right.$ each one), and dried at $60^{\circ} \mathrm{C}$ for $24 \mathrm{~h}$. Concluded the reaction time, propylamine functionalized silica was mixed with $60 \mathrm{~mL}$ of methyl acrylate/methanol solution $(1: 1, \mathrm{v} / \mathrm{v})$ and stirred under a nitrogen atmosphere at $50^{\circ} \mathrm{C}$ for $2 \mathrm{~h}$. The product was filtered and washed with methanol to obtain methylester functionalized silica. Secondary amide was obtained by the reaction of methylester functionalized solid with $15 \mathrm{~mL}$ of butylamine in $15 \mathrm{~mL}$ of methanol; the mixture was stirred at $50^{\circ} \mathrm{C}$ for $8 \mathrm{~h}$. The butylamide silica was filtered, washed with ethanol $(3 \times 10 \mathrm{~mL})$, and dried at $60^{\circ} \mathrm{C}$ for $24 \mathrm{~h}^{[26]}$

\section{Apparatus}

Infrared characterization of the butylamide silica synthesized was performed in a Perkin-Elmer Fourier transform infrared (FTIR) spectrophotometer model IRDM. The samples were analyzed in $\mathrm{KBr}(1 \%)$ sample pellets. The morphological analysis of the solid phase was performed using a scanning electron microscopy (SEM, FEI Model Quanta 200 F, Holland).

Electrophoresis was performed using a Beckman Coulter PA 800 plus (Fullerton, CA, USA) with a photo diode array detector. Data were collected and analyzed with Beckman PA system 10.1 version 32 Karat software. Separation of the SMX was performed in a fused silica capillary $(21.5 \mathrm{~cm} \times$ $75 \mu \mathrm{m}$ I.D.) using an electrolyte solution consisted of a phosphate buffer solution $(30 \mathrm{mM}, \mathrm{pH} 7.0)$. At the beginning of each working day, the capillary was activated with $\mathrm{NaOH}$ $1.0 \mathrm{M}$ at $25^{\circ} \mathrm{C}$ for $20 \mathrm{~min}$, followed by $\mathrm{NaOH} 0.1 \mathrm{M}$ for $10 \mathrm{~min}$ and deionized water at $25^{\circ} \mathrm{C}$ for $10 \mathrm{~min}$ and then electrolyte solution at $25^{\circ} \mathrm{C}$ for $10 \mathrm{~min}$. The capillary was washed out between sample analysis using: $\mathrm{NaOH} 1.0 \mathrm{M}$ for $3 \mathrm{~min}$, $\mathrm{NaOH} 0.1 \mathrm{M}$ for $1 \mathrm{~min}$, deionized water for $2 \mathrm{~min}$, and electrolyte solution for $2 \mathrm{~min}$. All flushing procedures were performed at a pressure of $20 \mathrm{psi}$.

The wavelength detector $(\lambda)$ was set at $214 \mathrm{~nm}$ to monitor SMX separation. Samples were injected in hydrodynamic mode under a pressure of $0.5 \mathrm{psi}$ for $5 \mathrm{~s}$. The capillary was kept at $25^{\circ} \mathrm{C}$, and a voltage of $15 \mathrm{kV}$ was applied to separate the analytes. The peak area ratio of analyte/internal standard was used in the quantification. The different peaks were identified by migration times, coinjection of standard solutions, and UV spectrum. A pH/ion analyzer model 450 from Corning (Corning Science Products, NY, USA) was used to accurately adjust the $\mathrm{pH}$ of the electrolyte solution to $0.01 \mathrm{pH}$ unit. A Cole-Parmer Ultrasonic system (Vernon Hills, Illinois, USA) model 8891 was used in the dispersion of samples. Finally, a Maxi-Mix I (Barnstead/Thermolyne, IA, USA) model M16715 was used as a vortex mixer in the dispersion of butyl silica.

\section{Sample analysis}

Milk samples $(10 \mathrm{~mL})$ were fortified with internal standard (doxycycline, $15 \mathrm{mg} \mathrm{L}^{-1}$ ) in polypropylene tubes. Proteins were precipitated by adding $2.0 \mathrm{~mL}$ of acetic acid $2 \%(\mathrm{v} / \mathrm{v})$, followed by heating for $5 \mathrm{~min}\left(65^{\circ} \mathrm{C}\right)$ and centrifuging at 


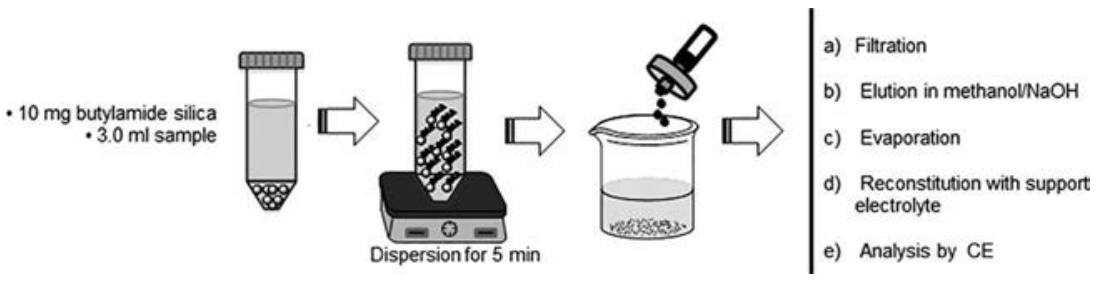

Figure 1. Schematic procedure for the isolation of SMX from milk samples using DSPE.

$3200 \mathrm{rpm}$ for $15 \mathrm{~min}$. Deproteinization helps to prevent the emulsion formation during sample treatment; additionally, the obtained aqueous matrix (acidic $\mathrm{pH}$ value) is suitable for extraction of the SMX by DSPE. ${ }^{[27,28]}$ Subsequently, $1.0 \mathrm{~mL}$ of the liquid phase was taken, adjusted the $\mathrm{pH}$ value at 2.0 (adding $\mathrm{H}_{3} \mathrm{PO}_{4} 1.0 \mathrm{M}$ ), and diluted to $10 \mathrm{~mL}$ with deionized water in a calibration flask (solution $\mathrm{A}$ ).

$10 \mathrm{mg}$ of butylamide silica was placed in polypropylene centrifuge tubes $(15 \mathrm{~mL})$ together with $3 \mathrm{~mL}$ of solution prepared earlier (solution A). The mixture was dispersed for $5 \mathrm{~min}$ in a vortex and filtered through a $0.45 \mu \mathrm{m}$ nylon membrane, the solid phase (containing the analyte and the IS) was isolated and SMX and IS were eluted from the butylamide silica by passing $3.0 \mathrm{~mL}$ of $\mathrm{NaOH} 0.1 \mathrm{M}$ in methanol through the membrane. The resulting solution was evaporated to dryness with moderate heating; subsequently the residue was reconstituted in $1.0 \mathrm{~mL}$ of support electrolyte (phosphate buffer, $30 \mathrm{mM}, \mathrm{pH}$ 7.0) and filtered through a nylon membrane, and finally analyzed by CE (Figure 1).

\section{Results and discussion}

\section{Characterization of the solid adsorbent}

The butylamide silica synthesized was characterized by FTIR spectroscopy (Figure 2). Infrared spectroscopy is a useful tool to identify the functional groups in silica phases. Figure $2 \mathrm{a}$ shows the spectrum of unmodified silica, a stretching band at $3600-3500 \mathrm{~cm}^{-1}$ was attributed to the vibration of the silanol group $(\mathrm{Si}-\mathrm{OH})$, a bending band at $1645 \mathrm{~cm}^{-1}$ was attributed to the water contained in the silica gel. In addition, a stretch band at $1300-1000 \mathrm{~cm}^{-1}$ belonging to the vibration of the siloxane group ( $\mathrm{Si}-\mathrm{O}-\mathrm{Si}$ ) as well as a band in $800 \mathrm{~cm}^{-1}$

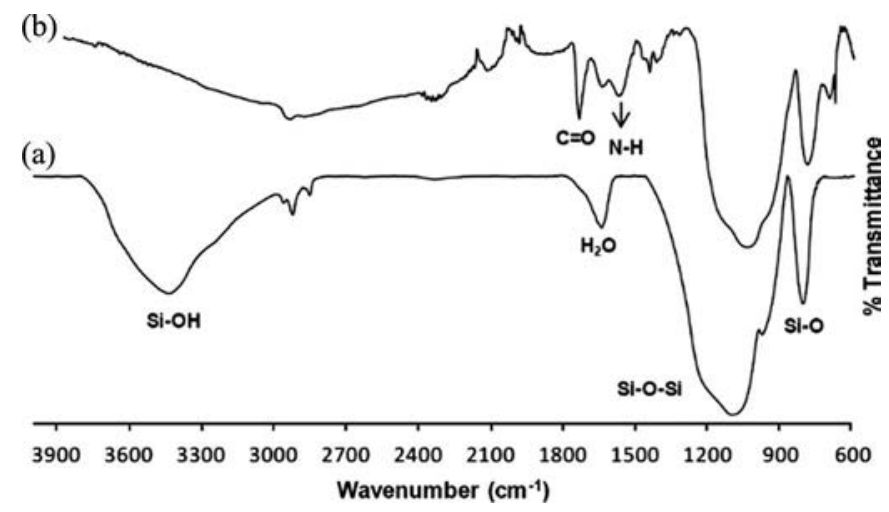

Figure 2. FTIR spectra of (a) unmodified silica and (b) butylamide silica synthesized. for the siloxide group ( $\mathrm{Si}-\mathrm{O})$. On the other hand, spectrum of Figure $2 \mathrm{~b}$ for butylamide silica solid shows a band at 1650 $1515 \mathrm{~cm}^{-1}$ attributed to the flexion of $\mathrm{N}-\mathrm{H}$ and another characteristic band of the amide group $(\mathrm{C}=\mathrm{O})$ corresponding to the vibration at $1710 \mathrm{~cm}^{-1}$. 29$]$

The morphology of the synthesized butylamide silica was analyzed by SEM. Figure 3 shows that solid has a granular morphology with spherical agglomerates. Particle sizes are irregular between 4 and $10 \mu \mathrm{m}$ (Figure $3 \mathrm{a}$ ), while the solid surface has granules of about $0.25 \mu \mathrm{m}$ (Figure $3 \mathrm{~b}$ ). This botryoidal phase contributes to form porous and in consequence the solid possesses high surface area. ${ }^{[30]}$

\section{Optimization of the DSPE method}

The DSPE involves diverse control variables which can affect the extraction and elution processes such as: composition and volume of sample and eluent, amount and type of solid phase and contact time during extraction and elution. To evaluate the effect of some control parameters in the extraction of SMX by DSPE, the effect of $\mathrm{pH}$ value and sample volume was studied (Figure 4). The $\mathrm{pH}$ value plays an important role in the extraction and isolation of the $\mathrm{SMX}^{[17,18]}$ because it has two ionizable groups (pKa values, 1.49, 5.48). ${ }^{[31]}$ Extraction experiments were performed in a $\mathrm{pH}$ range from 1.0 to 10.0 . Figure 4 shows that at $\mathrm{pH} 2.0$, the neutral form of SMX has higher affinity, indicating that charged SMX species (cationic at $\mathrm{pH}$ values below 1.49, and anionic above 5.48) causes lower extractions.

The influence of sample volume on the extraction of SMX (Figure 4) was studied in the range of 3 at $25 \mathrm{~mL}$ using $30 \mathrm{mg}$ of butylamide silica. The amount of SMX extracted were stable in all range evaluated, resulting in an extraction capacity of $0.56 \pm 0.02 \mu \mathrm{g}_{\mathrm{SMX}} \mathrm{mg}^{-1}$ solid. ${ }^{[32]}$ A sample volume of $3 \mathrm{~mL}$ was chosen for further analysis.

Once the appropriate extraction conditions, it was evaluated the following solvents in the elution of SMX from the solid: methanol, acetic acid (0.01 M in methanol), $\mathrm{NaOH}$ $(0.01 \mathrm{M}$ in methanol), acetonitrile, acetic acid $(0.01 \mathrm{M}$ in acetonitrile), and $\mathrm{NaOH}(0.01 \mathrm{M}$ in acetonitrile). Figure 5 shows the recovery of SMX using each of the elution solutions; better recoveries are obtained when basified solutions are used (73$85 \%$ with $\mathrm{NaOH}$ in acetonitrile and methanol, respectively). This behavior is associated with electrostatic repulsion at $\mathrm{pH}$ values above 5.48. Remain siloxide group acquires a negative charge, promoting a repulsion of SMX in its anionic form. ${ }^{[31]}$ According to the results, the following conditions were selected to perform the extraction-elution of SMX in milk samples: $\mathrm{pH}$ value, 2.0; sample volume, $3 \mathrm{~mL}$; dispersion time, $3 \mathrm{~min}$; 

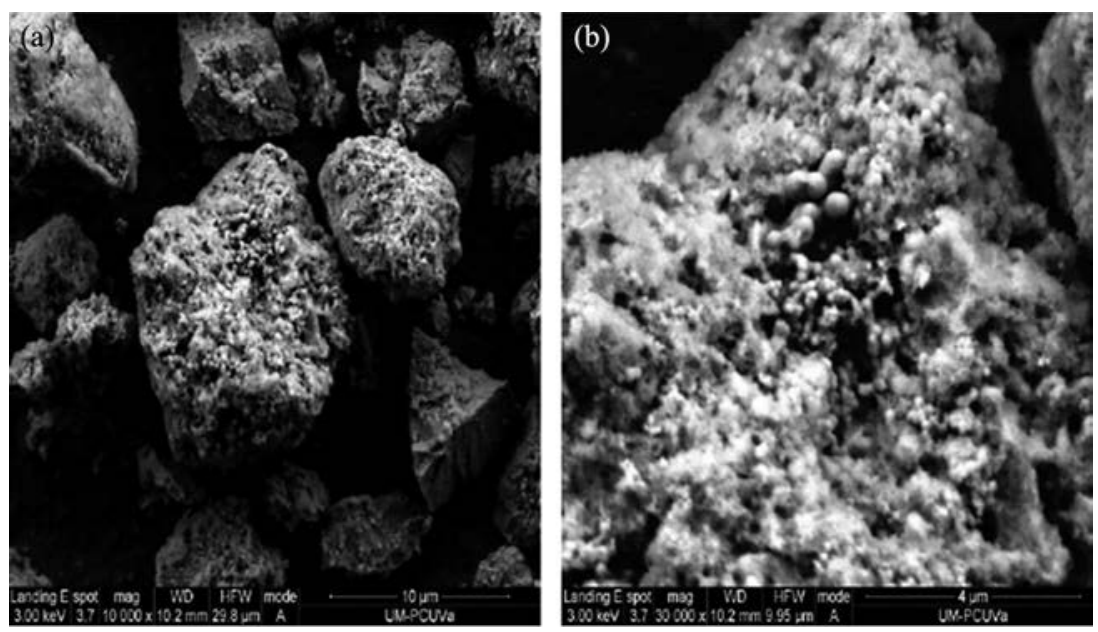

Figure 3. Micrographs for the butylamide silica.

amount of solid phase, $30 \mathrm{mg}$; and eluent composition, methanol-basified. These parameters were fixed to continue the optimization of SMX elution.

Taking into account the possible interaction between control factors, DSPE methodology was optimized using a fractional factorial design (Taguchi parameter design) because it can discriminate the effects of control factors, with a minimum of experiences. Taguchi parameter design uses matrices (orthogonal arrays) in which the columns (factors and their interactions) and the rows (experience) are placed in the properly manner, indicating the combination of factors and levels of each experiment. In this work, the orthogonal array $\mathrm{L}_{9}\left(3^{4}\right)$ was used to evaluate four control factors at three levels each. ${ }^{[33]}$ Control variables were selected according to the previous results: amount of solid phase, dispersion time, eluent composition, and eluent volume. The amount of butylamide silica (from 10 to $50 \mathrm{mg}$ ) was chosen because of it affects the efficiency in the extraction; the concentration of $\mathrm{NaOH}$ in methanol $(0.001-0.1 \mathrm{M})$ was considered because it is associated with the electrostatic repulsion between the solid phase and the SMX; elution volume $(1-3 \mathrm{~mL})$ and dispersion time
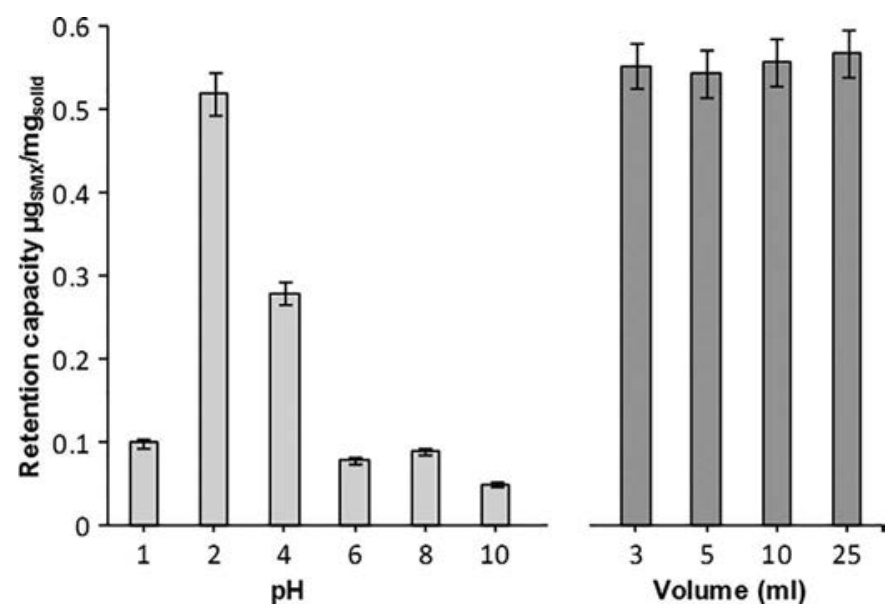

Figure 4. Effect of $\mathrm{pH}$ and volume on the extraction of SMX. Conditions: butylamide silica $30 \mathrm{mg}$; SMX $7 \mathrm{mg} \mathrm{L}^{-1}$.
(1-5 min) were selected to ensure the maximum retention of SMX in the butylamide silica. ${ }^{[34]}$

All experiments were performed analyzing $10 \mathrm{~mL}$ of a milk sample doped with SMX at $7 \mathrm{mg} \mathrm{L}^{-1}$. Once the extraction is complete, the retained SMX was eluted under conditions previously described in the experimental section and analyzed by CE. Output variable was the relationship of signal areas (SMX/IS) which is desired to be maximum. Table 1 shows the design matrix and the area ratio obtained for each trial. All experiments were performed in duplicate and the total number of experiments was 18 (9 experiments $\times 2$ replicates).

Table 2 shows that values of the variance ratio $\left(F_{\text {calculated }}\right)$ are higher than critical variance $\left(F_{\text {critical }}=4.26\right.$ for a $95 \%$ confidence level), which denote that all the control factors evaluated are critical. The factors of higher influence on the response are $\mathrm{NaOH}$ concentration in methanol and amount of butylamide silica, which accounted 46.75 and $30.63 \%$, respectively. The contribution of residual error was $0.05 \%$; this value is associated with the proper selection of control factors.

Figure 6 shows the analysis of means obtained for DSPE methodology. Optimal levels selected were butylamide silica amount of $10 \mathrm{mg}, \mathrm{NaOH}$ concentration of $0.1 \mathrm{M}$ in methanol, $3 \mathrm{~mL}$ of elution volume, and $5 \mathrm{~min}$ of dispersion time. An increase in the butylamide silica amount would result in a

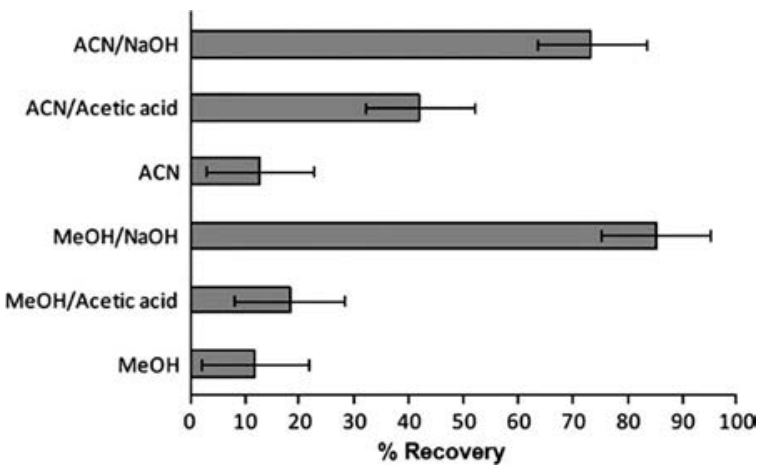

Figure 5. Elution solvent evaluated for DSPE experiments. 
Table 1. Orthogonal design matrix $L_{9}\left(3^{4}\right)$ used for the optimization of the DSPE methodology proposed $(n=2)$.

\begin{tabular}{llllrc}
\hline \multicolumn{5}{c}{ Control factors and levels } & \\
\cline { 1 - 4 } $\operatorname{Exp}$ & $S_{\mathrm{M}}$ & $C_{[\mathrm{OH}-\mathrm{]}}$ & $E_{\mathrm{V}}$ & $D_{\mathrm{T}}$ & Area (SMX/IS) \\
\hline 1 & 10 & 0.001 & 1 & 1 & 0.2216 \\
2 & 10 & 0.01 & 2 & 3 & 0.1155 \\
3 & 10 & 0.1 & 3 & 5 & 0.8908 \\
4 & 30 & 0.001 & 2 & 5 & 0.0281 \\
5 & 30 & 0.01 & 3 & 1 & 0.0334 \\
6 & 30 & 0.1 & 1 & 3 & 0.1064 \\
7 & 50 & 0.001 & 3 & 3 & 0.1344 \\
8 & 50 & 0.01 & 1 & 5 & 0.0433 \\
9 & 50 & 0.1 & 2 & 1 & 0.4228 \\
\hline
\end{tabular}

$\mathrm{S}_{\mathrm{M}}$, butyl silica amount $(\mathrm{mg}) ; \mathrm{C}_{[\mathrm{OH}-\mathrm{]}}, \mathrm{NaOH}$ concentration in methanol $\left(\mathrm{mol} \mathrm{L}^{-1}\right)$ $E_{\mathrm{V}}$, elution volume $(\mathrm{mL}) ; D_{\mathrm{T}}$, dispersion time $(\mathrm{min})$.

lower dispersion between solid and phases and also higher desorption solution volumes would be needed. ${ }^{[32,35]}$ In the case of volume and dispersion time variables, highest values are needed to promote the contact between the analyte and the solid. Additionally, the level selected of $\mathrm{NaOH}$ concentration in methanol must be highest to form negative charges which promote repulsion between the solid and SMX. The results demonstrate the existence of possible hydrogen bond interactions between the solid and SMX.

\section{Validation and application of method}

Under the optimal conditions, analytical parameters of the DSPE-CE method were evaluated using a sample volume of $10.0 \mathrm{~mL}$ of spiked milk with SMX in the range of concentration of $0.10-34.0 \mathrm{mg} \mathrm{L}^{-1}$. Each standard was prepared and analyzed in triplicate. The regression parameters of the calibration lines are shown in Table 3. A linear dependence of the peak area ratio and the concentration of SMX, in the doped milk sample, were obtained. The limit of detection was calculated from the relation $S_{\mathrm{e}} / b_{1}(3.29)$, where $S_{\mathrm{e}}$ is the square root of the residual variance of the standard curve, and $b_{1}$ is the slope, in accordance with the recommendations of IUPAC. ${ }^{[36]}$

The accuracy of the method was determined by the absolute recovery of SMX added to a sample of blank milk (previously analyzed by the proposed method) at two concentration levels with three replicates for each level $\left(7\right.$ and $\left.23 \mathrm{mg} \mathrm{L}^{-1}\right)$. The average recovery obtained for the SMX in doped milk samples was found in a range of $70 \%$ at $85 \%$ with relative standard deviations (RSD) of 1.85 and $2.3 \%$, respectively. Precision is adequate for the analysis of complex samples $(\mathrm{RSD}<5 \%)$ in all cases using the proposed DSPE-CE methodology.

Table 2. Regular variance analysis (pooled ANOVA).

\begin{tabular}{lccccc}
\hline $\begin{array}{l}\text { Variance } \\
\text { source }\end{array}$ & $\begin{array}{c}\text { Degree } \\
\text { of } \\
\text { freedom }\end{array}$ & $\begin{array}{c}\text { Sum of } \\
\text { squares }\end{array}$ & Variance & $\begin{array}{c}\text { Variance } \\
\text { ratio }(F)^{a}\end{array}$ & $\begin{array}{c}\text { Influence } \\
(\%)^{b}\end{array}$ \\
\hline$S_{\mathrm{M}}$ & 2 & 0.38 & 0.19 & 2671.88 & 30.63 \\
$C_{[\mathrm{OH}-\mathrm{C}}$ & 2 & 0.58 & 0.29 & 4078.13 & 46.75 \\
$E_{\mathrm{V}}$ & 2 & 0.16 & 0.08 & 1125.00 & 12.90 \\
$D_{\mathrm{T}}$ & 2 & 0.12 & 0.06 & 843.75 & 9.67 \\
Residual & 9 & $6.4 \times 10^{-4}$ & $7.11 \times 10^{-5}$ & & 0.05 \\
Total & 17 & 1.24 & 0.07 & & 100.00 \\
\hline
\end{tabular}

${ }^{a}$ The critical variance ratio for a $95 \%$ confidence level is 4.26 (2,9 d.f.).

${ }^{b}$ Contribution is defined as $100 \times$ (sum of squares/total sum of squares).

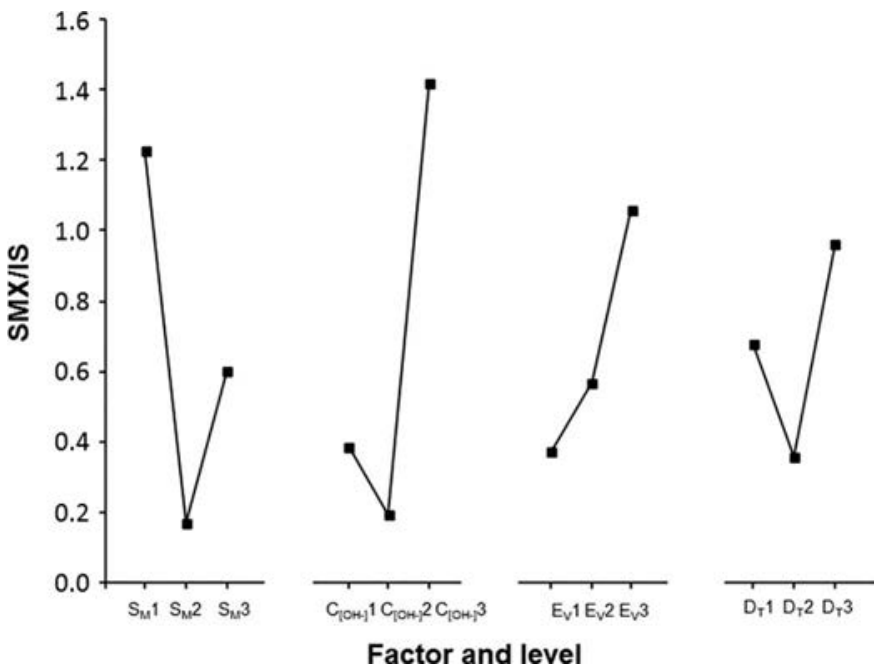

Figure 6. Effects of control factors on the output variable during DSPE-CE. $S_{M}$, solid mass; $C_{[\mathrm{OH}-]}, \mathrm{NaOH}$ concentration in methanol; $E_{\mathrm{V}}$, elution volume; $D_{\mathrm{T}}$ dispersion time.

Table 3. Regression parameters of the calibration lines obtained in doped milk sample.

\begin{tabular}{lc}
\hline Regression parameter & Value \\
\hline Correlation coefficient, $r^{2}$ & 0.998 \\
Square root of residual variance, $S_{\mathrm{e}}$ & 0.034 \\
Intercept, $b_{0}\left(\mathrm{mg} \mathrm{L}^{-1}\right)$ & $0.105 \pm 0.001$ \\
Slope, $b_{1}\left(\mathrm{Abs} \mathrm{L} \mathrm{mg} \mathrm{m}^{-1}\right)$ & $1.882 \pm 0.051$ \\
Repeatability intraday (RSD (\%) $\left.n=3,15 \mathrm{mg} \mathrm{L}^{-1}\right)$ & 1.17 \\
Repeatability interday (RSD (\%) $\left.n=3,15 \mathrm{mg} \mathrm{L}^{-1}\right)$ & 0.95 \\
Linearityrange $\left(\mathrm{mg} \mathrm{L}^{-1}\right)$ & $0.10-34.0$ \\
Limit of detection $\left(\mathrm{mg} \mathrm{L}^{-1}\right)$ & 0.05 \\
Limit of quantification $\left(\mathrm{mg} \mathrm{L}^{-1}\right)$ & 0.10 \\
\hline
\end{tabular}

Area SMX: Area IS vs [SMX]: [IS] in concentration $\left(\mathrm{mg} \mathrm{L}^{-1}\right)$.

Electropherograms obtained in the determination of SMX in doped milk samples under optimal conditions are shown in Figure 7. Figure 7a shows interferences presented by the components of a real milk sample during SMX analysis without DSPE treatment. Figure $7 \mathrm{~b}$ shows a blank milk sample treated by a proposed DSPE-CE methodology (without IS). Figure $7 \mathrm{c}$ displayed the electropherogram of the analysis of a spiked milk sample. An effective cleanup and separation of

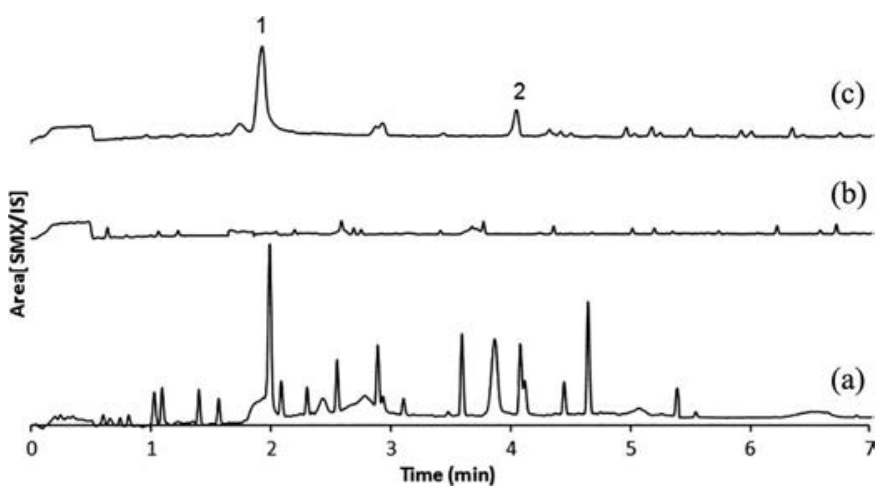

Figure 7. Electropherograms obtained from the analysis of SMX by DSPE-CE: (a) milk sample, (b) blank milk sample, and (c) spiked milk sample $\left(7 \mathrm{mg} \mathrm{L}^{-1}\right)$; 1 doxycycline (IS), 2 sulfamethoxazole. 


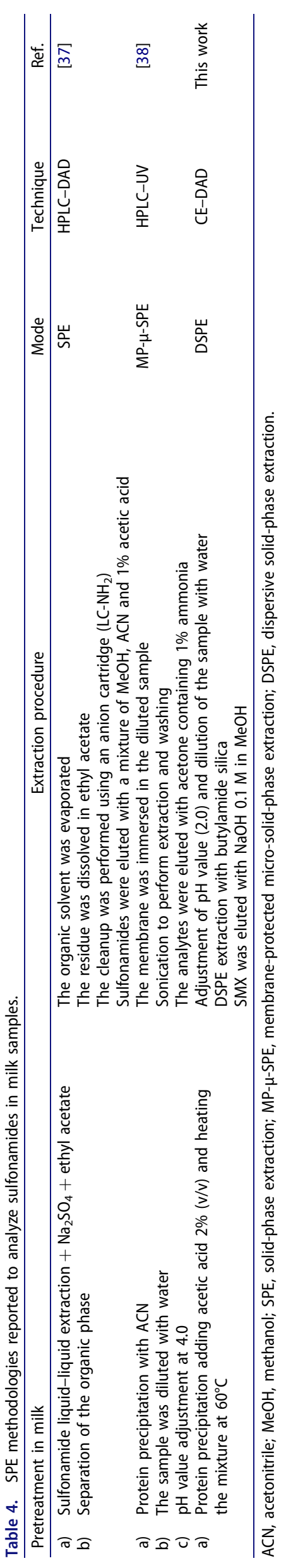


SMX from milk samples is verified, demonstrating the selectivity of the butylamide silica during DSPE-CE analysis. Milk cleanup using the butylamide silica is similar than other SPE techniques based on anion-exchange $\left(-\mathrm{NH}_{2}\right)$ mechanism and polymeric membrane in combination with HPLC (Table 4). The proposed DSPE-CE methodology has the advantage of low consumption of organic solvents.

The proposed methodology was applied to the determination of SMX in 12 commercial milk samples from different brands. Three replicate determinations were performed on each sample. According to the results obtained by analysis of SMX in milk, 1 of the 12 samples tested was positive with concentration of $145.3 \pm 0.04 \mu \mathrm{g} \mathrm{kg}-1$.

\section{Conclusions}

The proposed methodology DSPE-CE, based on butylamide silica, was applied successfully in the cleanup/extraction and analysis of SMX in milk samples. Electrostatic interactions are critical in the methodology proposed. Butylamide silica retains SMX through hydrogen bond interactions. The DSPE-CE technique has advantages such as similar cleanup capacity, lower reagent consumption, and analysis time respect to HPLC methods.

\section{Funding}

The authors wish to thank PRODEP (Project RedNIQAE-2015) and Junta de Castilla y Leon, (project VA171U14) for the financial support.

\section{References}

[1] García-Galán, M. J.; Díaz-Cruz, M. S. Identification and Determination of Metabolites and Degradation Products of Sulfonamides Antibiotics. TrACTrends Anal. Chem. 2008, 27, 1008-1022.

[2] Kaneene, J. B., Miller, R. Description and Evaluation of the Influence of Veterinary Presence on the Use of Antibiotics and Sulfonamides in Dairy Herds. J. Am. Vet. Med. Assoc. 1992, 201, 68-71.

[3] Shahani, K. M., Whalen, P. J. Significance of Antibiotics in Foods and Feeds. In: Agricultural Uses of Antibiotics. ACS Symposium Series; Moats, W. A. Ed.; American Chemical Society: Washington, 1986, pp. 88-99.

[4] Pereira, A. V., Cass, Q. B. High-Performance Liquid Chromatography Method for the Simultaneous Determination of Sulfamethoxazole and Trimethoprim in Bovine Milk Using an On-Line Column. J. Chromatogr. B 2005, 826, 139-146.

[5] Cai, M., Zhu, L., Ding, Y., Wang, J., Li, J., Du, X. Determination of Sulfamethoxazole in Foods Based on $\mathrm{CeO}_{2} /$ Chitosan Nanocomposite-Modified Electrodes. Mater. Sci. Eng. C 2012, 32, 2632-2627.

[6] Iglesias, A., Nebot, C., Miranda, J. M., Vázquez, B. I., Cepeda, A. Detection and Quantitative Analysis of 21 Veterinary Drugs in River Water Using High-Pressure Liquid Chromatography Coupled to Tandem Mass Spectrometry. Environ. Sci. Pollut. Res. 2012, 19, 3235-3249.

[7] Upadhyay, K., Asthana, A., Tiwari, N. Solid Phase Extractive Spectrophotometric Determination of Some Sulfa Drugs. Asian J. Pharm. Clin. Res. 2012, 5, 222-226.

[8] Conzuelo, F., Gamella, M., Campuzano, S., Pinacho, D. J., Reviejo, A. J., Marco, M. P., Pingarron, J. M. Disposable and Integrated Amperometric Immunosensor for Direct Determination of Sulfonamide Antibiotics in Milk. Biosens. Bioelectron. 2012, 36, 81-88.

[9] Wang, L., Wu, J., Wang, Q., He, C., Zhou, L., Wang, J., Pu, Q. Rapid and Sensitive Determination of Sulfonamides Residues in Milk and
Chicken Muscle by Microfluidic Chip Electrophoresis. J. Agric. Food Chem. 2012, 60, 1613-1618.

[10] Ibarra, I. S., Miranda, J. M., Rodríguez, J. A., Nebot, C., Cepeda, A. Magnetic Solid phase Extraction Followed by High-Performance Liquid Chromatography for the Determination of Sulfonamides in Milk. Food Chem. 2014, 157, 511-517.

[11] Liu, J., Jiang, M., Li, G., Xu, L., Xie, M. Miniaturized Salting-OutLiquid-Liquid Extraction of Sulfonamides from Different Matrices. Anal. Chim. Acta 2010, 679, 74-80.

[12] Haller, M. Y., Muller, S. R., McArderll, C. S., Alder, A. C., Suter, M. J. F. Quantification of Veterinary Antibiotics (Sulfonamides and Trimethoprim) in Animal Manure by Liquid Chromatography Mass Spectrometry. J. Chromatogr. A 2002, 952, 111-120.

[13] Zayas-Blanco, F., García-Falcón, M. S., Simal-Gándara, J. Determination of Sulfamethazine in Milk by Solid Phase Extraction and Liquid Chromatographic Separation with Ultraviolet Detection. Food Control 2004, 15, 375-378.

[14] Zhang, Y., Liu, H., Zhang, X., Lei, H., Bai, L., Yang, G. On-Line Solid Phase Extraction Using Organic-Inorganic Hybrid Monolithic Columns for the Determination of Trace $\beta$-Lactam Antibiotics in Milk and Water Samples. Talanta 2013, 104, 17-21.

[15] Vidal, L., Riekkola, M. L., Canals, A. Ionic Liquid-Modified Materials for Solid-Phase Extraction and Separation: A Review. Anal. Chim. Acta 2012, 71, 19-41.

[16] Plotka-Wasylka, J., Szczepanska, N., De la Guardia, M., Namiesnik, J. Miniaturized Solid-Phase Extraction Techniques. Trends Analyt. Chem. 2015, 73, 19-38.

[17] Herrera-Herrera, A. V., Hernández-Borges, J., Afonso, M. M., Palenzuela, J. A., Rodriguez-Delgado, M. A. Comparison between Magnetic and Nonmagnetic Multi-Walled Carbon Nanotubes-Dispersive Solid-Phase Extraction Combined with Ultra-High of Sulfonamide Antibiotics in Water Samples. Talanta 2013, 116, 695-703.

[18] Xiao-Lin, H., Yin-Liang, W., Ting, Y., Xiang-Dang, D. Multi-Walled Carbon Nanotubes-Dispersive Solid-Phase Extraction Combined with Liquid Chromatography-Tandem Mass Spectrometry for the Analysis of 18 Sulfonamides in Pork. J. Chromatogr. B 2013, 929, 107-115.

[19] Dagnac, T., Garcia-Chao, M., Pulleiro, P., Garcia-Jares, C., Llompart, M. Dispersive Solid-Phase Extraction Followed by Liquid Chromatography-Tandem Mass Spectrometry for the Multi-Residue Analysis of Pesticides in Raw Bovine Milk. J. Chromatogr. A 2009, 1216, 3702-3709.

[20] Snyder, L. R., Dolan, J. W., Carr, P. W. The Hydrophobic-Subtraction Model of Reversed-Phase Column Selectivity. J. Chromatogr. A 2004, 1060, 77-116.

[21] Rimmer, C. A., Sander, L. C. Shape Selectivity in Embedded Polar Group Stationary Phases for Liquid Chromatography. Anal. Bioanal. Chem. 2009, 394, 285-291.

[22] Kirkland, J. J. Development of Some Stationary Phases for ReversedPhase HPLC. J. Chromatogr. A 2004, 1060, 9-21.

[23] Aturki, Z., D’Orazio, G., Rocco, A., Si-Ahmed, K., Fanali, S. Investigation of Polar Stationary Phases for the Separation of Sympathomimetic Drugs with Nano-Liquid Chromatography in Hydrophilic Interaction Liquid Chromatography Mode. Anal. Chim. Acta 2011, 685, 103-110.

[24] Martínez-Villalba, A., Moyano, E., Galceran, M. T. Analysis of Amprolium by Hydrophilic Interaction Liquid ChromatographyTandem Mass Spectrometry. J. Chromatogr. A 2010, 1217, 5802-5807.

[25] Ibarra, I. S., Rodriguez, J. A., Miranda, J. M., Vega, M., Barrado, E. Magnetic Solid Phase Extraction Base on Phenyl Silica Adsorbent for the Determination of Tetracyclines in Milk by Capillary Electrophoresis. J. Chromatogr. A 2011, 1218, 2196-2202.

[26] Islas, G., Rodríguez, J. A., Cruz-Borbolla, J., Vásquez-Pérez, J. M., Barrado, E. Synthesis and Characterization of Amide Stationary Phases for the Determination of Sulfonamides by Sequential Injection Chromatography. Anal. Lett. 2016, 49, 676-689.

[27] Wen-Hsien, T., Tzou-Chi, H., Joh-Jong, H., Yi-Huu, H., Hung-Yi, C. Dispersive Solid-Phase Microextraction Method for Sample Extraction in the Analysis of Four Tetracyclines in Water and Milk Samples by High-Performance Liquid Chromatography 
with Diode-Array Detection. J. Chromatogr. A 2009, 1216, 2263-2269.

[28] Granja, R. H. M. M., de Lima, A. C., Salerno, A. G., Wanschel, C. B. A. Validation of a Liquid Chromatography with Ultraviolet Detection Methodology for the Determination of Sulfonamides in Bovine Milk According to 2002/657/EC. Food Control 2012, 28 , 304-308.

[29] Xu, L., Peng, R., Guan, X., Tang, W., Liu, X., Zhang, H. Preparation, Characterization, and Application of a New Stationary Phase Containing Different Kinds of Amine Groups. Anal. Bioanal. Chem. 2013, 405, 8311-8318.

[30] Huang, Z., Zhou, H., Chen, Z., Zeng, F., Chen, L. Facile Synthesis of Porous Pt Botryoidal Nanowires and their Electrochemical Properties. Electrochim. Acta 2014, 147, 643-649.

[31] Sanli, S., Altun, Y., Sanli, N., Alsancak, G., Beltran, J. L. Solvent Effects on $\mathrm{pK}_{\mathrm{a}}$ Values of Some Substituted Sulfonamides in Acetonitrile-Water Binary Mixtures by UV-Spectroscopy Method. J. Chem. Eng. 2009, 54, 3014-3020.

[32] Liu, F. J., Liu, C. T., Li, W., Tang, A. N. Dispersive Solid-Phase Microextraction and Capillary Electrophoresis Separation of Food Colorants in Beverages Using Diamino Moiety Functionalized Silica Nanoparticles as Both Extractant and Pseudostationary Phase. Talanta 2015, 132, 366-372.
[33] Massart, D. L., Vandeginste, B. G. M., Buydens, L. M. C., De Jong, S., Lewi, P. J., Smeyers-Verbeke. Handbook of Chemometrics and Qualimetrics Part A. Editorial Elsevier: Amsterdam, 1997; Vol. 20A, 799-803 pp.

[34] Zhang, M., Chen, J., Mallik, A. K., Qiu, H., Jiang, S., Ihara, H. Preparation and Chromatographic Evaluation of New Branch-Type Diamide-Embedded Octadecyl Stationary Phases with Enhanced Shape Selectivity. Anal. Chim. Acta 2014, 833, 48-55.

[35] Pardasani, D., Kanaujia, P. K., Purohit, A. K., Shrivastava, A. R., Dubey, D. K. Magnetic Multi-Walled Carbon Nanotubes Assisted Dispersive Solid Phase Extraction of Nerves Agents and their Markers from Muddy Water. Talanta 2011, 86, 248-255.

[36] Currie, L. A. Nomenclature in Evaluation of Analytical Methods Including Detection and Quantification Capabilities (IUPAC Recommendation). Pure Appl. Chem. 1995, 67, 1699-1723.

[37] Yin-Liang, W., Cun, L., Yong-Jun, L., Jian-Zhong, S. Validation Method for the Determination of Sulfonamide Residues in Bovine Milk by HPLC. Chromatographia 2007, 66, 191.

[38] Jiangeng H., Juanjuan L., Cong Z., Jiaojiao W., Li M., Shan Y., Gao L., Li X. 2012. Determination of Sulfonamides in Food Samples by Membrane-Protected Micro-Solid Phase Extraction Coupled with High Performance Liquid Chromatography. J. Chromatogr. A 2012, 1219, 66-74. 